\title{
Variations of the Geomagnetic Dipole Magnitude over the Past 400 My
}

\author{
A. A. Schreider ${ }^{a}$, Al. A. Schreider ${ }^{b}$, P. Varga ${ }^{c}$, C. Denis ${ }^{d}$ \\ a Shirshov Institute of Oceanology, Russian Academy of Sciences, Moscow, Russia \\ ${ }^{b}$ Geological Faculty, Moscow State University, Moscow, Russia \\ ${ }^{c}$ Seismological Observatory, Institute for Geodesy and Geophysics, Hungarian Academy of Sciences, Budapest, Hungary \\ ${ }^{d}$ Institute for Astrophysics, Liege University, Liege, Belgium \\ e-mail:aschr@ocean.ru
}

Received June 29, 2006; in final form, August 2, 2007

\begin{abstract}
The international bank of the virtual dipole moment data supplemented by the values from more recent publications is used as the basis for an analysis of the behavior of the virtual dipole moment values over the last $400 \mathrm{My}$. The results obtained revealed a positive linear trend from $4.1 \times 10^{22}$ to $5.7 \times 10^{22} \mathrm{~A} \mathrm{~m}^{2}$ during the last $400 \mathrm{My}$. Against the background of the linear increase, fluctuations with a periodicity of about $40 \mathrm{My}$ were observed. In the Phanerozoic time, minimums within the intervals of 340-370, 290-300, 240-270, 190-210, 165-140 (chrons M17-M43), 130-120 (chrons M2-M10), 100-110 (chron 34), 75-85 (chron C33 and the beginning of chron C34), 70-60 (chrons C31-C27), and 40-15 (chrons C18-C5AD) My B.P. are found. The distribution of the virtual dipole moment is strictly related to the distribution of the ancient geomagnetic field and may be taken into consideration when modeling the magnetization of the inversive magnetic layer of the ocean.
\end{abstract}

DOI: $10.1134 / \mathrm{S} 0001437008020124$

\section{INTRODUCTION}

The expansion of the earth's magnetic field into a series with respect to spherical harmonics suggests that the first spherical harmonic of the geomagnetic field is equivalent to the field of a magnetic dipole placed at the center of the earth. Thus, the main part of the earth's magnetic field, to a first approximation, is described by the field of an axisymmetric dipole. An important characteristic of the magnetic field is the time history of the values of the virtual dipole moment (VDM), which is regarded as the dipole moment of the equivalent geocentric dipole that produced the known magnetic and inclination of the vector of the ancient dipole field [15] for a specified moment in the past. The results of the operation of the magnetic dynamo in the geological past are represented by the values of the virtual dipole moment recovered in the process of the studies of magnetic properties of the earth's rocks. These kinds of data on the distribution of the dipole component of the earth's magnetic field over time bring evidence about its significant variations in the Phanerozoic $[3,4,7,11$, $14,17,19,21-24]$. Until recently, the great scattering of individual VDM values has allowed only a qualitative estimation of any regularity. In paper [3], a general methodological approach to the VDM data processing was suggested and the results of its application to a VDM analysis for the interval of 0-200 My B.P. were demonstrated. The objective of this study is to use the quantitative approach described in [3] while analyzing such regularities for the interval of 0-400 My B.P.

\section{MATERIALS USED}

Recently, in order to examine the time history of VDM, an international database (IAGA PALEOINTENSITY DATABASE) was created; it is available at the site of the Geophysical Center in Boulder (Colorado) [12]. In the middle of 2006, this database contained 2825 VDM values for the last 400 My collected from 237 published sources [9]. This database, together with additional information from the database of the Borok Observatory [6] and the data published in $[11,16,18]$, formed the base for this study. The updated database used by us included 3203 VDM values with corresponding absolute age determinations.

A qualitative analysis of the data shows that the value of the earth's magnetic field intensity was not constant in time. Meanwhile, the quantitative analysis of the qualitative regularities was deteriorated by the significant scattering of the actual individual values of the virtual dipole moment (Fig. 1).

Among other approaches to their interpretation, the sliding average method allows one to significantly smooth irregular fluctuations of the data used. We chose it as the main operation method used. Numerous estimates [3] made by us showed that the best size of the sliding window for averaging the data available for the 


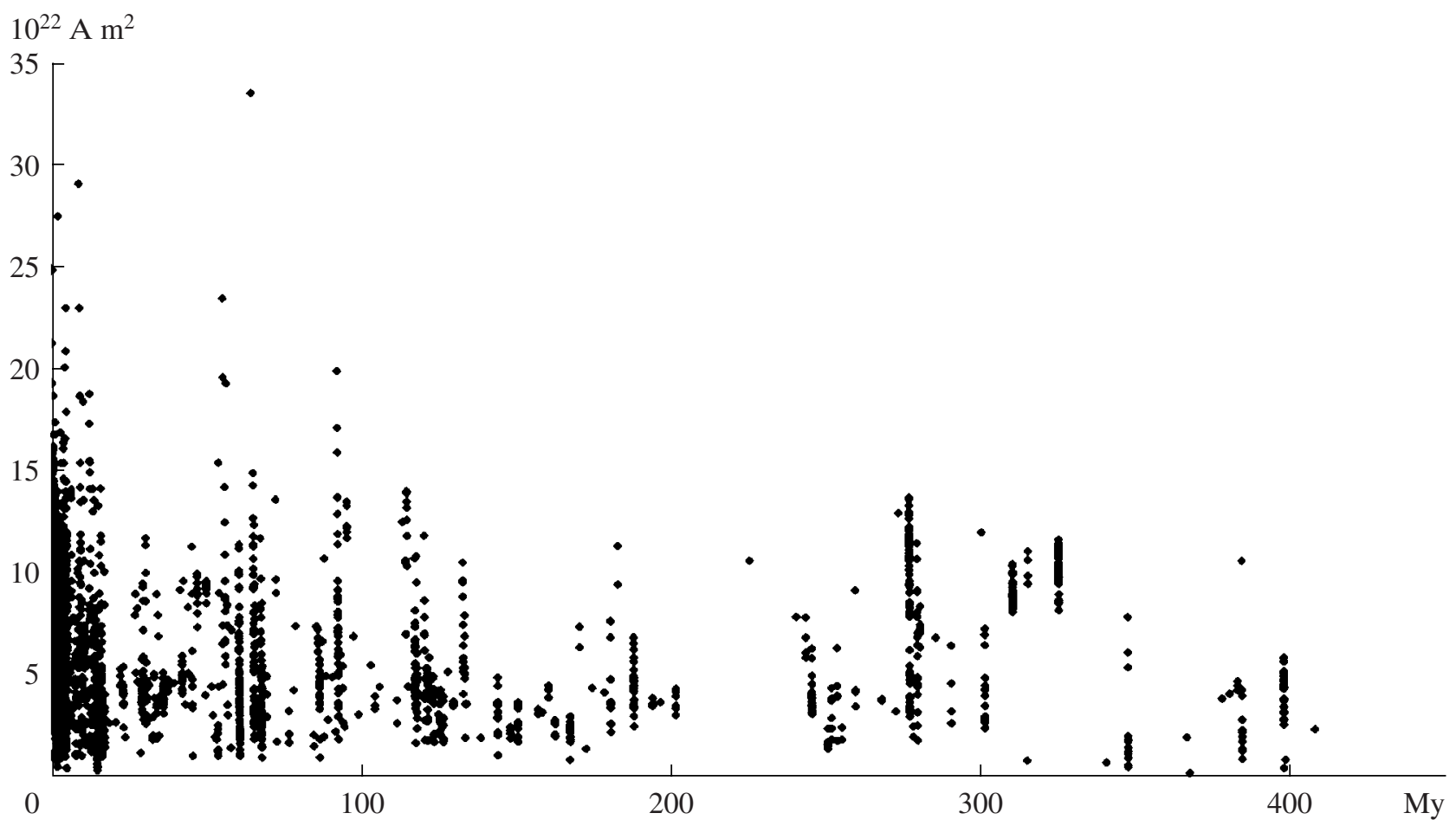

Fig. 1. Distribution of the values of the virtual dipole moment according to the extended database used in this paper.

interval down to 400 My B.P. is 10 My and the optimal sliding step comprises $5 \mathrm{My}$. With these parameters, in each calculation, one can involve, as a rule, no less than $10-50$ values and strongly eliminate random fluctuations from the resulting curve. In this study, we used the scale of linear magnetic anomalies and corresponding polarity subchrons from $[2,8]$.

The maximal numbers of values used by us in this analysis fall in the intervals of 0-10 My B.P. (1858 values), 10-20 My B.P. (227 values), 60-70 My B.P. (179 values), and 275-285 My B.P. (110 values). The intervals of 220-230, 260-270, 265-275, 285-295, 310-320, 335-345, 360-370, 365-375, and 400-410 My B.P. are characterized by less than 7 values each; the intervals of 205-230, 330-340, 350-360, and 385-395 My B.P. contained no values available for calculations.

In all of the cases, we used mean VDM values and their standard deviations in the averaging interval. These values were referred to the average age values determined for the corresponding averaging intervals.

The modal value of the standard deviations of the age values from their means falls into the interval of $\pm 0.32- \pm 0.57 \mathrm{My}$. There are five values exceeding \pm 1 My: \pm 1.13 My B.P. in the interval of 75-85 My B.P., $\pm 1.5 \mathrm{My}$ in the interval of $170-180$ My B.P., $\pm 1.05 \mathrm{My}$ in the interval of 95-105 My B.P., \pm 1.49 My in the interval of 160-170 My B.P., and \pm 1.43 My in the interval of 270-280 My B.P.

\section{RESULTS OF THE CALCULATIONS}

Figure 2 shows the distribution of the mean VDM values in the window $10 \mathrm{My}$ wide with a shift of $5 \mathrm{My}$ plotted using the data of our updated database containing 3203 values. The vertical bars denote the standard deviations, whose values represent the width of the scattering of individual values from their mean. The horizontal axis is the age corresponding to the mean age in the averaging window.

The plot proves that the virtual dipole moment, whose present-day value equals $8 \times 10^{22} \mathrm{~A} \mathrm{~m}^{2}$ [14], was not constant in the past. Over the last $400 \mathrm{My}$, the mean VDM values are characterized by the presence of a positive linear trend from $4.1 \times 10^{22}$ to $5.7 \times 10^{22} \mathrm{~A} \mathrm{~m}^{2}$ toward the present-day epoch; 225 My B.P., it reached its maximal values of $10.58 \times 10^{22} \mathrm{~A} \mathrm{~m}^{2}$, while the minimal values of $0.98 \times 10^{22} \mathrm{~A} \mathrm{~m}^{2}$ are confined to $366.5 \mathrm{My} \mathrm{B.P.}$ Against this background, one can note significant fluctuations of the mean VDM values with a wavelength (the distance between the peaks of similar signs) of $20 \mathrm{My}$ and greater.

In the Paleozoic, the peaks are determined for the Famenian-Tournaisian (370-340 My B.P.; peak with an absolute value up to $2.2 \times 10^{22} \mathrm{~A} \mathrm{~m}^{2}$ and a relative amplitude of about $2 \times 10^{22} \mathrm{~A} \mathrm{~m}^{2}$ ), Visean-Gzhelian (340-300 My B.P.; peak with an absolute value up to $10.2 \times 10^{2} \mathrm{~A} \mathrm{~m}^{2}$ at a relative amplitude of about $8 \times 10^{22} \mathrm{~A} \mathrm{~m}^{2}$ ), and Sakmarian-Hoongurian (290-270 My B.P.; peak with an absolute value up to $7.9 \times 10^{22} \mathrm{~A} \mathrm{~m}^{2}$ at a relative amplitude of about $4 \times 10^{22} \mathrm{~A} \mathrm{~m}^{2}$ ). 


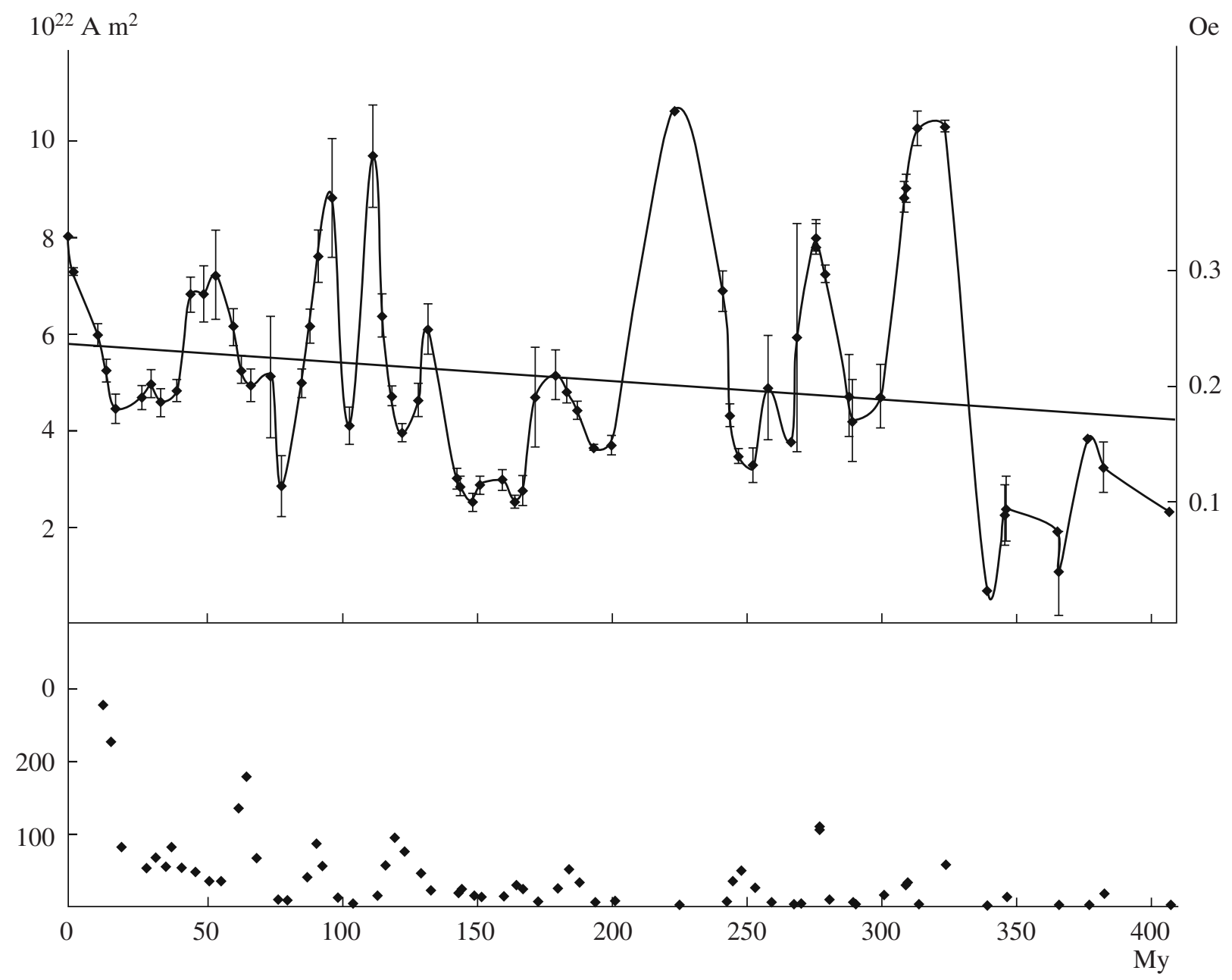

Fig. 2. Distribution of the mean values of the virtual dipole moment for the period of $0-400$ My B.P. The values are calculated using the sliding average method with a window $10 \mathrm{My}$ wide at a step of $5 \mathrm{My}$. The right-hand vertical axis represents VDM values converted into the equatorial intensity of the paleomagnetic field in $10^{3}$ mOe. The vertical bars show the representativeness errors or root-mean-square deviations from the average value for each of the calculation windows. The dots below the time axis show the numbers of values in each of the calculation windows except for the windows of 0-10 My B.P. (1858 values); 5-15 My B.P. (278 values); 10-20 My B.P. (227 values); 60-70 My B.P. (157 values); and 205-225, 235-240, 330-340, 350-360, and 385-395 My B.P. (no values).

In the Mesozoic, the peaks are confined to the Indian-Gettanguan (251-200 My B.P.; peak with an absolute value up to $10.6 \times 10^{22} \mathrm{~A} \mathrm{~m}^{2}$ at a relative amplitude of about $6.5 \times 10^{22} \mathrm{~A} \mathrm{~m}^{2}$ ), SinemurianBathonian (195-165 My B.P.; peak with an absolute value up to $5.1 \times 10^{22} \mathrm{~A} \mathrm{~m}^{2}$ at a relative amplitude of about $2 \times 10^{22} \mathrm{~A} \mathrm{~m}^{2}$ ), Tithonian-Barremian (150-123 My B.P.; peak with an absolute value up to $6 \times 10^{22} \mathrm{~A} \mathrm{~m}^{2}$ at a relative amplitude of about $3 \times 10^{22} \mathrm{~A} \mathrm{~m}^{2}$ ), Aptian-Albian (123-103 My B.P.; peak with an absolute value up to $9.6 \times$ $10^{22} \mathrm{~A} \mathrm{~m}^{2}$ at a relative amplitude of about $6 \times 10^{22} \mathrm{~A} \mathrm{~m}^{2}$ ), Albian-Campanian (103-78 My B.P.; peak with an absolute value up to $8.8 \times 10^{22} \mathrm{~A} \mathrm{~m}^{2}$ at a relative amplitude of about $5 \times 10^{22} \mathrm{~A} \mathrm{~m}^{2}$ ), and Campanian-Maestrichtian (78-67 My B.P.; peak with an absolute value up to $5.1 \times 10^{22} \mathrm{~A} \mathrm{~m}^{2}$ at a relative amplitude of about $4 \times 10^{22} \mathrm{~A} \mathrm{~m}^{2}$ ).
In the Cenozoic, a peak with an absolute value up to $7.2 \times 10^{22} \mathrm{~A} \mathrm{~m}^{2}$ and a relative amplitude of about $2.5 \times 10^{22} \mathrm{~A} \mathrm{~m}^{2}$ is recognized in the Danian-Priabonian (67-33 My B.P.). Starting from 16.9 My B.P., the VDM value grew from 4 to $8 \times 10^{22} \mathrm{~A} \mathrm{~m}^{2}$ at present.

Between the above-listed peaks, minimums of the VDM are located. The shape of the extreme parts of the minimums is more complicated than that of the maximums and often contains additional local peaks with an amplitude up to $0.5 \times 10^{22} \mathrm{~A} \mathrm{~m}^{2}$. The distribution obtained (Fig. 2), to a significant degree, refines the previous data from $[4,5,10]$ about the variations of the VDM in this interval.

\section{DISCUSSION OF THE RESULTS}

The results of the calculations of the mean VDM values obtained using the sliding average method sug- 
gest that they are not chaotic in time and demonstrates a linear 1.4-fold VDM growth during the last $400 \mathrm{My}$ toward the present-day epoch. Against the background of this growth, one observes fluctuations with a period estimated at approximately $40 \mathrm{My}$.

The magnitude of the virtual dipole moment and the modulus of the intensity of the ancient magnetic field $\mathrm{H}_{\mathrm{an}}$ for the same age and at the same latitude are directly related to each other, which allows one to use the VDM to characterize the intensity of the main (dipole) component of the ancient magnetic field. We will express the corresponding values in the shares of the present-day intensity $\mathrm{H}_{\mathrm{pd}}$, whose equatorial value equals 0.33 Oe $(26.3 \mathrm{~A} / \mathrm{m})$ [1]. The linear trend in the increase of the intensity of the dipole component of the earth's magnetic field at the equator over the past 400 My may be estimated as $0.132 \mathrm{mOe} / \mathrm{ky}$.

In the Paleozoic, these fluctuations are represented by the region of reduced values (down to 0.2 of $\mathrm{H}_{\mathrm{pd}}$ ) in the interval of 370-340 My B.P. and down to 0.4 of the $\mathrm{H}_{\mathrm{pd}}$ in the intervals of 300-290, 270-240, and 210190 My B.P.

In the Mesozoic, the fluctuations are represented by the region of values reduced down to 0.3 of the $\mathrm{H}_{\mathrm{pd}}$ in the interval of 165-140 My B.P. (chrons M43-M17). Regions of relative lows of the field intensity down to 0.5 of the $\mathrm{H}_{\mathrm{pd}}$ are registered for the intervals of 130-120 (chrons M10-M2) and 100-110 (chron C34) My B.P.; values down to 0.35 of the $\mathrm{H}_{\mathrm{pd}}$ are recognized for the interval of 75-86 My B.P. (chron C33 and the beginning of chron C34).

In the Cenozoic, these kinds of regions include the area of values reduced down to 0.7 of the $\mathrm{H}_{\mathrm{pd}}$ at the boundary of the Danian and the Maestrichtian in the interval of 70-60 My B.P. (chrons C31-C27) and the area of values reduced down to 0.5 of the $\mathrm{H}_{\mathrm{pd}}$ in the interval of 40-14 My B.P. (chrons C18-C5AD). Let us emphasize once more that, in the central parts of the minimums at 370-340, 270-240, 165-144, and 40-14 My B.P., one encounters areas of elevated values.

During the past $400 \mathrm{My}$, the total durations of the periods of the maximums and minimums of the VDM are close to one another. The significant (from $10 \times 10^{22} \mathrm{~A} \mathrm{~m}^{2}$ and higher to $0.3 \times 10^{22} \mathrm{~A} \mathrm{~m}^{2}$ and lower) variations of the dipole component of the Earth's magnetic field directly suggests the necessity of accounting for these variations when modeling paleomagnetic anomalies formed in the axial spreading zones in the MesozoicCenozoic as well as when modeling the inversive magnetic layer of the portions of the oceanic crust of more remote geological epochs that might have existed on our planet.

\section{CONCLUSIONS}

An analysis of the data of the updated digital database on the virtual dipole moment brings evidence that the distribution of the VDM values over the past
$400 \mathrm{My}$ is characterized by the presence of a positive linear trend from $4.1 \times 10^{22}$ to $5.7 \times 10^{22} \mathrm{~A} \mathrm{~m}^{2}$. Against the background of the linear growth, fluctuations with periods approximately estimated at $40 \mathrm{My}$ are manifested.

The VDM distribution obtained using the sliding average method reflects the behavior of the ancient magnetic field; it should be taken into account when modeling magnetization values of the inversive magnetic layer of the ocean for the chron interval of C1-M43. The values of the VDM referring to times greater than 165 My B.P. (chron M43) may be used for magnetic modeling of the inversive magnetic layer for the portion of the oceanic crust of the geological past that might have existed on our planet.

\section{ACKNOWLEDGMENTS}

This study was performed within the frameworks of the Agreement on Joint Studies (project no. 38) and was supported by the Hungarian Scientific Foundation (project no. OLKA K60394).

\section{REFERENCES}

1. A. A. Logachev and V. P. Zakharov, Magnetic Prospecting (Nedra, Leningrad, 1979) [in Russian].

2. A. A. Shreider Geomagnetic Studies of the Indian Ocean (Nauka, Moscow, 2001) [in Russian].

3. A. A. Shreider, Al. A. Shreider, P. Varga, and C. Denis, "Variations in the Magnitude of the Geomagnetic Dipole in the Interval of Chrons C1-M43," Okeanologiya 45 (5), 785-789 (2005) [Oceanology 45 (5), 745-749 (2005)].

4. V.P. Shcherbakov, G. M. Solodovnikov, and N. K. Sycheva, "Variations in the Magnitude of the Geomagnetic Dipole over the Past 400 My (Volcanic Rocks)," Fiz. Zemli, No. 2, 26-33 (2002).

5. L. Alva-Valdivia, A. Goguitchaichvili, and J. UrrutiaFucugauchi, "Further Constraints for the Plio-Pleistocene Geomagnetic Field Strength: New Results from the Los Tuxtlas Volcanic Field (Mexico),' Earth Planets Space 53, 873-881 (2001).

6. Borokpint. http://www.brk.adm.yar.ru/palmag/index/html.

7. C. Denis, A. A. Schreider, P. Varga, and J. Zavoti, "Despinning of the Earth Rotation in the Geological Past and Geomagnetic Paleointensities," J. of Geodynamics 34, 667-685 (2002).

8. F. Gradstein, J. Ogg, A. Smith, et al., "A New Geologic Time Scale with Special Reference to Precambrian and Neogene," Episodes 27 (2), 83-100 (2004).

9. IAGA paleointensity database http://www.isteem.univmontp 2.fr/PERSO/perrin/

10. M. Juarez and L. Tauxe, "The Intensity of Time Averaged Geomagnetic Field: The Last 5 Myr," Earth Planet. Sci. Lett. 175, 169-180 (2000).

11. Y. Pan, M. Hill, R. Zhu, and J. Shaw, "Future Evidence for Low Intensity of the Geomagnetic Field during the Early Cretaceous Time: Using the Modified Shaw 
Method and Microwave Technique," Geophys. J. Int. 157, 553-564 (2004).

12. M. Perrin and E. Schnepp, "IAGA Paleointensity Database: Distribution and Quality of the Data Set," Phys. Earth Planet. Inter. 147, 255-267 (2004).

13. G. Plenier, P. Camps, R. Coe, and M. Perrin, "Absolute Paleointensity of Oligocene (28-30 Ma) Lava Flows from the Kerguelen Archipelago (Southern Indian Ocean)," Geophys. J. Int. 154, 877-890 (2003).

14. P. Selkin and L. Tauxe, "Long-Term Variations in Paleointensity," Phil. Trans. R. Soc. Lond (2000).

15. P. Smith, "The Intensity of the Tertiary Geomagnetic Field,” Geophys. J. R. Astr. Soc. 12, 239-258 (1967).

16. A. Taki, H. Shibuya, A. Yoshihara, and Y. Hamano, "Paleointensity Measurements of Piroclastic Flow Deposits Co-Born with Widespread Tephras in Kyushu Island, Japan," Physics of the Earth and Planet. Int. 133, 159-179 (2002).

17. H. Tanaka and M. Kono, "Paleointensities from a Cretaceous Basalt Platform in Inner Mongolia, Northeastern China," Earth Planet. Sci. Lett. 133, 147-157 (2002).

18. J. Tarduno and R. Cotterell, "Dipole Strength and Variation of the Time-Averaged Reversing and Nonreversing
Geodynamo Based on Thellier Analyses of Single Plagioclase Crystals," J. Geophys. Res. 110, 10 (2005).

19. J. Valet, "Time Variations in Geomagnetic Intensity," Reviews in Geophysics 41 (1), 44 (2003).

20. P. Varga, B. Sule, and A. A. Schreider, "Short-Term (Decadal) and Long- Term (Over Geological History) Correspondence of Length of Day and Geomagnetic Field," Geophys. Res. Abstracts 8, 02230 (2006).

21. P. Varga, J. Zavoti, C. Denis, and A. A. Schreider, Complex Interpretation of the Earth Despinning History. Vistas for Geodesy in the New Millennium (Springer, Berlin, 2002), pp. 417-422.

22. R. Zhu, K. Hoffman, S. Nomande, et al., "Geomagnetic Paleointensity and Direct Age Determination of the ISEA (M0r) Chron," Earth Planet. Sci. Lett. 217, 285-295 (2004).

23. R. Zhu, K. Hoffman, Y. Pan, et al., "Evidence for Weak Geomagnetic Field Intensity Prior to the Cretaceous Normal Superchron," Earth Planet. Sci. Lett. 136, 187-199 (2003).

24. R. Zhu, Y. Pan, J. Shaw, et al., "Geomagnetic Paleointensity Just Prior to the Cretaceous Normal Superchron," Phys. Earth and Planet. Int. 128, 207-222 (2001). 
Reproduced with permission of the copyright owner. Further reproduction prohibited without permission. 